ËESTI NSV TEADUSTE AKADEEMIA TOIMETISED, 21. KÖIDE

KEEMIA * GEOLOOGIA. 1972, NR. 3

ИЗВЕСТИЯ АКАДЕМИИ НАУК ЭСТОНСКОН ССР. ТОМ 21

Химия * ГЕОЛОГИя. 1972, № 3

удК 543.551

ХЕЛЬЮ РАУДЕ, О. ЭИЗЕН, Т. САКС, А. ТАЛВАРИ

\title{
ПОЛУЧЕНИЕ ЧИСТЫХ ЦИКЛОПЕНТЕНОВЫХ УГЛЕВОДОРОДОВ МЕТОДОМ ПРЕПАРАТИВНОЙ ГАЗОВОЙ ХРОМАТОГРАФИИ
}

В соответствии с программой изучения физико-химических свойств ненасыщенных углеводородов были синтезированы следующие циклопентеновые углеводороды: 1- и 3-метил-, -этил-, -пропил-, -изопропил-, -бутил-, -изобутил-, -амил-, -изоамил-, -гексил-, -аллил-, -фенил- и -бензилциклопентены. Соединения с заместителем в 1-положении циклопентенового кольца были синтезированы из циклопентанона и соответствующего алкил-Mg-галогенида [ $\left.{ }^{1}\right]$. Соединения с заместителем в 3-положении были изготовлены из 3-хлорциклопентена и соответствующего алкилMg-бромида [²].

Синтезированные продукты предварительно очищались дистилляцией. Очистка их ректификацией весьма затруднительна и не дает всегда желаемых результатов, поэтому в настоящей работе изучалась возможность получения чистых циклопентеновых углеводородов методом препаративной газовой хроматографии.

Препаративной очистке предшествовала разработка методики разделения циклопентеновых углеводородов на аналитическом газовом хроматографе. Данных по газохроматографическому разделению циклопентеновых углеводородов в литературе опубликовано мало. В [3] приведено разделение изомерных 1-, 3- и 4-метилциклопентенов и метиленциклопентана, а также 1-, 3- и 4-этилциклопентенов и этилиденциклопентана на колонке с $\mathrm{AgNO}_{3}$ и гликолем. Колонки с $\mathrm{AgNO}_{3}$ в настоящей работе не использовались из-за недостаточной термической стойкости.

Ранее для разделения и очистки некоторых 1-алкилциклопентенов нами применялась четырехметровая препаративная колонка с твином 80 . В данном случае мы пытались подобрать стационарную фазу, которая была бы селективной к исследуемым соединениям при достаточной термической стойкости. Таким является, например, 1, 2, 3-трис(2-цианэтокси) пропан с максимально допустимой температурой колонок $180^{\circ} \mathrm{C}\left[{ }^{4}\right]$. На 1, 2, 3-трис(2-цианэтокси) пропане хорошо разделяются 1- и 3-изомеры алкилциклопентенов (рис. 1). На этой же фазе разделяются даже геометрические изомеры $н$-алкенов (рис. 2).

Целью данного исследования было разделение синтезированных циклопентенов от загрязняющих их примесей. Одной из трудно отделяющихся примесей 1-алкилциклопентенов является соответствующей алкилиденциклопентан, присутствие которого было установлено методом гидрогенизации в микрореакторно-газохроматографическом режиме. Разделение синтезированных 1-алкилциклопентенов и соответствующих алкилиденциклопентанов на колонке с 1,2,3-трис(2-цианэтокси)пропаном иллюстрирует рис. 3. Оно ухудшается с ростом длины алкильной цепи. 
Это обстоятельство оказывает существенное влияние на количество вещества, вводимое в препаративный хроматограф за один цикл и, следовательно, на выход очищенного продукта и его чистоту. В связи с этим пришлось пользоваться двойным хроматографированием 1-бутил-, 1амил- и 1-гексилциклопентенов для получения препаратов нужной степени чистоты. В дополнение к полярной
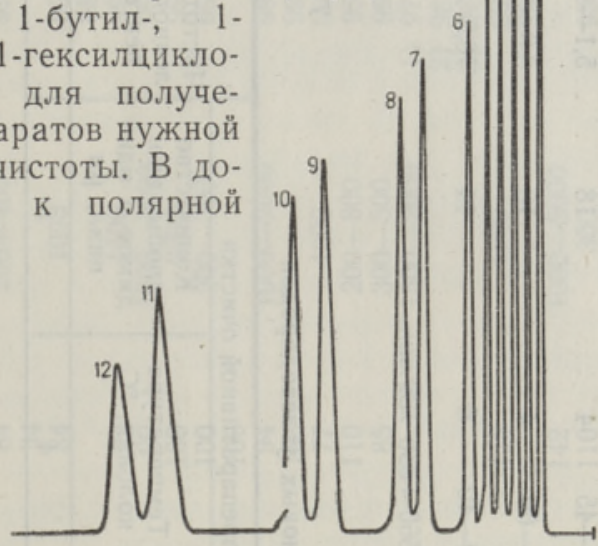

Рис. 1. Хроматограмма смеси 1- и 3-алкилциклопентенов. Колонка 1 (см. табл. 1), Т $81{ }^{\circ} \mathrm{C}$, скорость газа-носителя $\left(\mathrm{N}_{2}\right)$ 55 мл/мин. Пики: $1-3$-метилциклопентен, 2 - 1-метилциклопентен, 3 - 3-этилциклопентен, 4 - 1-этилцикпопентен, $5-3$-нпропилциклопентен, $6-1$-н-пропилциклопентен, $7-3-н$-бутилциклопентен, $8-1-\mu$ бутилциклопентен, $9-3$-н-амилциклопентен, $10-1$-н-амилциклопентен, $11-3-н$ гексилциклопентен, $12-1$-н-гексилциклопентен.

колонке с 1,2,3-трис(2-цианэтокси)пропаном была изготовлена колонка с апиезоном $L$ главным образом для очистки высококипящих циклопентенов (1- и 3-изомеры фенил-, бензил- и гексилциклопентенов), которая оказалась пригодной и для очистки 1-метил-, 3-метил-, 1-изопропил-, 3-изопропил-, 3-н-амил- и 3-изоамилциклопентенов.

В настоящей работе препаративное разделение осуществлялось на хроматографе PGK-3 Выруского завода газоанализаторов. Чистота исходных и очищенных алкилциклопентенов определялась на хроматографе «Хром-3», снабженном пламенно-ионизационным детектором. Характеристика проматографических колонок для анализа и очистки циклопентенов приведена в табл. 1.

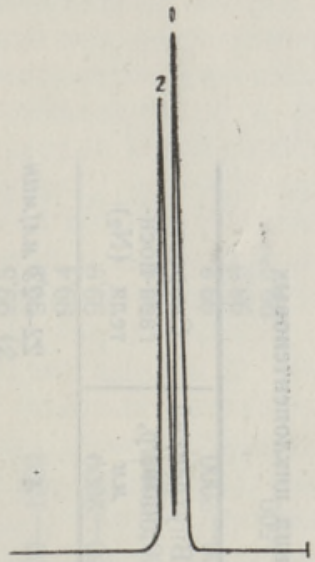

Рис. 2. Хроматограмма геометрических изомеров октена-2. Колонка I (см. табл. 1), Т $70^{\circ} \mathrm{C}$, скорость газа-носителя $\left(\mathrm{N}_{2}\right)$ 60 мл/мин. Пики: $1-$ октен-2(транс), 2 октен-2 (цис).

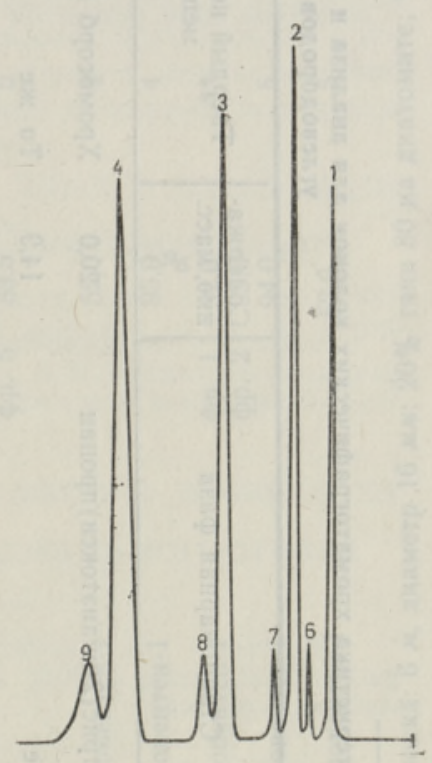

Рис. 3. Хроматограмма смеси 1-алкилциклопентенов. Колонка 1 (см. табл. 1), Т $75^{\circ} \mathrm{C}$, скорость газа-носигеля $\left(\mathrm{N}_{2}\right) 55$ мл/мин. Пики: 1 - 1-этилциклопентен, 2 1-н-пропилциклопентен, 3 1-н-бутилциклопентен, $4-$

1-н-амилциклопентен, $6-9$

- соответствующие алкилиденциклопентаны. 


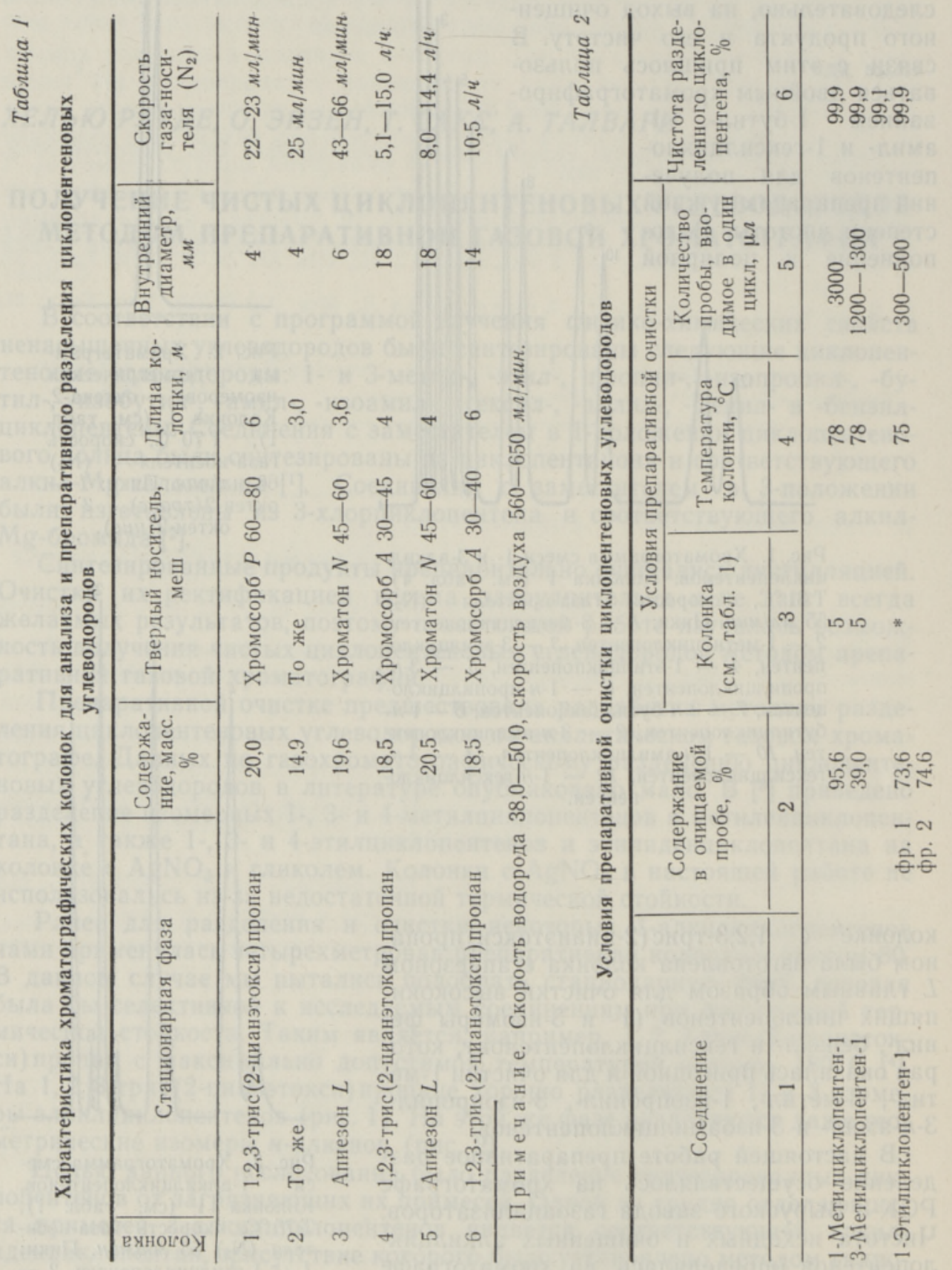


क. ช

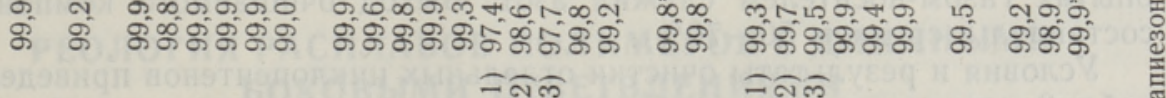

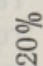

ఫิ 虽

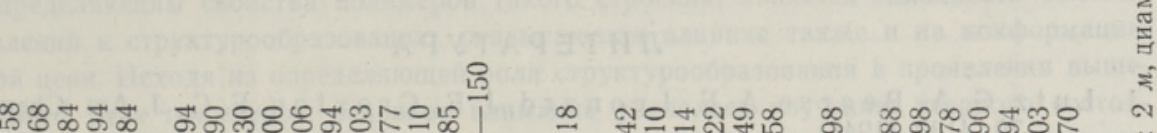

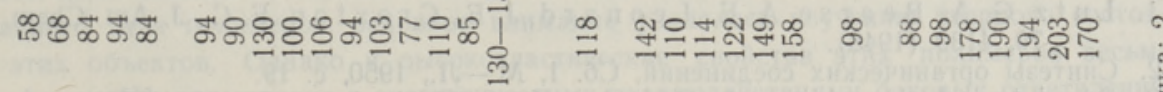

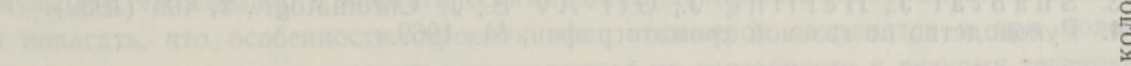

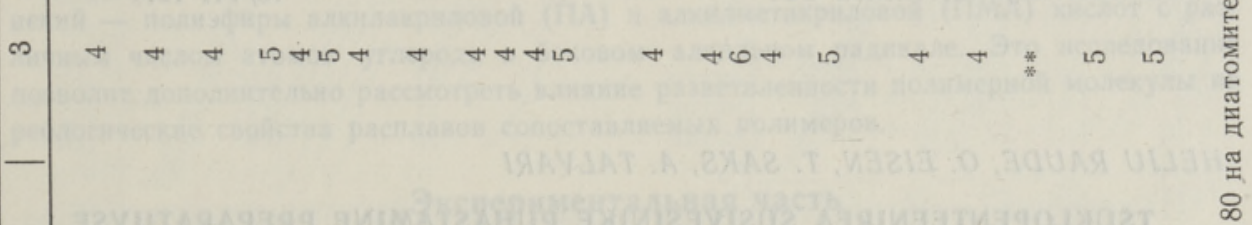
m \&े 安 ㅇํำ

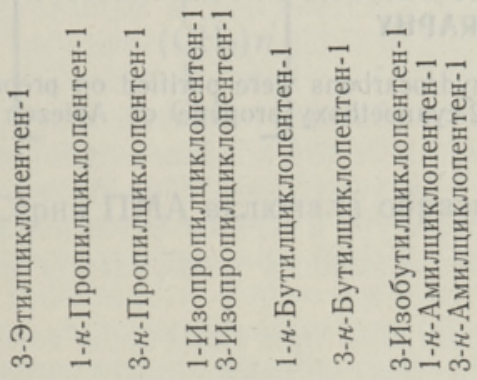
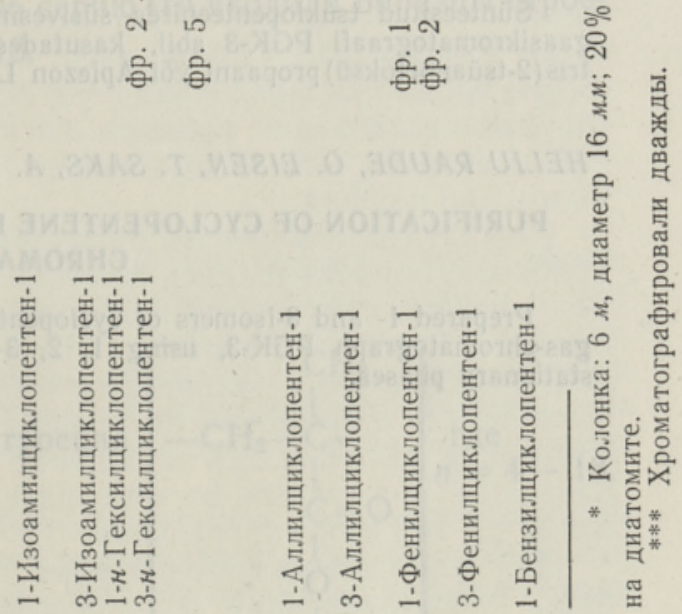
После предварительного анализа пробы вводились в препаративный хроматограф при помощи шприца. Количество вводимого в колонку циклопентена составляло $150-3000 \mu л$ в зависимости от количества примесей и их отделения от очищаемого компонента. Стеклянные ловушки охлаждались льдом, смесью льда с сслью или смесью ацетона с твердой углекислотой. Для ускоренного удаления следующих за главным компонентом примесей изменялось направление потока газа-носителя. Во всех опытах газом-носителем служил азст. Выход очищаемого компонента составлял в среднем 50-70\%.

Условия и результаты очистки отдельных циклопентенов приведены в табл. 2, откуда следует, что большинство полученных соединений характеризуется высокой степенью чистоты. В связи с этим использованную методику можно считать пригодной для получения чистых циклопентеновых углеводородов в миллилитровых количествах. Целесообразной является также предварительная очистка вещества, которая способствует получению более чистых конечных продуктов.

\section{ЛИ ТЕ Р А Т РА}

1. Lutz G. A., Bearse A. E., Leonard J. E., Croxton F. C., J. Am. Chem. Soc. $70,4139(1948)$.

2. Синтезы органических соединений, Сб. 1, М.-Л., 1950, с. 19.

3. Shabtai J., Herling J., Gil-Av E., J. Chromatogr., 2, 406 (1959).

4. Руководство по газовой хроматографии, М., 1969.

$\begin{array}{cc}\text { Ннститут химии } & \text { Поступила в редакщию } \\ \text { Академии наук Эстонской СCP } & 15 / \mathrm{VII} 1971\end{array}$

HELJU RAUDE, O. EISEN, T. SAKS, A. TALVARI

\section{TSUKLOPENTEENIREA SUSIVESINIKE PUHASTAMINE PREPARATIIVSE GAASIKROMATOGRAAFI ABIL}

Sünteesitud tsüklopenteenirea süsivesinike 1- ja 3-isomeerid puhastati preparatiivse gaasikromatograafi PGK-3 abil, kasutades kolonnides statsionaarsete faasidena 1,2,3tris (2-tsüanoetoksü) propaani vổi Apiezon L.

HELJU RAUDE, O. EISEN, T. SAKS, A. TALVARI

\section{PURIFICATION OF CYCLOPENTENE HYDROCARBONS BY PREPARATIVE GAS CHROMATOGRAPHY}

Prepared 1- and 3-isomers of cyclopentene hydrocarbons were purified on preparative gas-chromatograph PGK-3, using 1, 2, 3-tris(2-cyanoethoxy)propane or Apiezon L as stationary phases. 